\title{
ВОЗМОЖНОСТИ МЕТОДА РАДИОКИП ПРИ ИЗУЧЕНИИ ВЕРХНЕЙ ЧАСТИ РАЗРЕЗА В РУДНЫХ РАЙОНАХ
}

\author{
Давыдов Вадим Анатольевич, \\ davyde@yandex.ru \\ Институт геофизики им. Ю.П. Булашевича Уральского отделения РАН, \\ Россия, 620016, г. Екатеринбург, ул. Амундсена, 100.
}

Актуальность исследования обусловлена экономическим интересом к использованию простых, эффективных и высокопроизводительных геофизических технологий для поиска и разведки рудных месторождений.

Цель: оценить информативность геоэлектрических разрезов, построенных по импедансным данным метода радиокомпарации и пеленгации (радиокип), при изучении коры выветривания и кровли коренных пород в различных геологических условиях. Объекты исследования находятся в Дегтярско-Полевском рудном районе Среднего Урала, в приконтактовой зоне СеровскоМаукского разлома, разделяющего комплексы пород Тагильского прогиба и Восточно-Уральского поднятия. Геофизические профили располагались на территории Крылатовского золотокварцевого месторождения, Чусовского медно-колчеданного месторождения, Кунгурском и Волчихинском участках.

Методы. Полевые измерения методом радиокип проводились широкополосным приемником "ОМАР-2м» со стелющейся линией и индукционным датчиком переменного магнитного поля. Осуществлялись наблюдения ортогональных компонент поля сигналов сверхдлинноволновых радиостанций. В качестве сравнения использовались результаты аудиомагнитотеллурических и вертикальных электрических зондирований, а также информация по геологическому изучению территории. Количественная обработка электроразведочных данных осуществлялась с применением программного обеспечения, разработанного в различных научных учреждениях

Результаты. Проведенные исследования показали хорошую сопоставимость результатов инверсии радиокип сверхдлинноволновых радиостанций с геоэлектрическими разрезами, полученными другими методами электромагнитных зондирований. Радиокип не может отобразить всех особенностей строения верхней части разреза, но позволяет выделить характерные черты коренных пород и определить основную границу между рыхлыми отложениями и основанием разреза. Полученные результаты указывают на принципиальную возможность обнаружения глубокозалегающих рудных объектов с помощью метода радиокип сверхдлинноволновых радиостанций. Метод отличается хорошей производительностью, поэтому можно добиться высокой детальности наблюдений при небольших затратах. Геоэлектрические разрезы радиокип могут использоваться для оперативной оценки общей мощности коры выветривания и выбора точек зондирований другими электромагнитными методами для уточнения геологической обстановки.

\section{Ключевые слова:}

Метод радиокомпарации и пеленгации сверхдлинноволновых радиостанций, компоненты электромагнитного поля, импеданс, геоэлектрический разрез, рудные месторождения

\section{Введение}

Метод радиокомпарации и пеленгации (радиокип) удаленных радиостанций был разработан в 50-х гг. ХХ в. Основные принципы и примеры применения метода радиокип достаточно подробно изложены в ряде отечественных и зарубежных публикаций [1-4]. Поначалу использовались средневолновые (СВ) и длинноволновые (ДВ) вещательные станции, с середины 60-х гг. используются сигналы специальных сверхдлинноволновых радиостанций (СДВР). Диапазон частот СДВР находится в пределах 10-30 кГц, что позволяет исследовать разрез на глубину до 50-100 м. Станции применяются в системах навигации и радиосвязи, а также для передачи сигналов эталонных частот и единого времени. Наиболее мощные радиостанции уверенно принимаются на расстоянии свыше 10000 км. За рубежом радиокип СДВР называется методом VLF (Very Low Frequency) - «очень низких частот». Модификация радиокип СДВР с измерением только магнитных компонент носит обозначение VLF-EM (ElectroMagnetic), для изучения импеданса электромагнитных полей служит вариант VLF-R (Resistivity). В VLF-EM обычно измеряют отношение между вертикальной $\left(H_{z}\right)$ и тан- генсальной составляющей горизонтального магнитного поля $\left(H_{\varphi}\right)$, называемого типпером. Получаемые данные служат для определения параметров эллипса поляризации магнитного поля: угла наклона и эллиптичности, которые напрямую связаны с реальными и мнимыми компонентами типпера [5]. Чтобы связать аномалии типпера с проводящими и непроводящими объектами были предложены специальные методы фильтрации профильных данных. Для площадного картирования обычно используется фильтрация Фрейзера [6], а для построения псевдоразрезов проводимости Karous-Hjelt $(K H)$ фильтрация [7]. Развитие данной технологии шло в направлении повышения устойчивости от технических и геологических помех. Одним из предложенных способов было использование эмпирической модовой декомпозиции $(E M D)$ сигналов на основе преобразований Гильберта-Хуанга (Hilbert-Huang transform HHT) $[8,9]$. Проведенный анализ возможностей HНT на примере геофизических данных показал, что эмпирическая модовая декомпозиция обеспечивает устойчивую адаптивную очистку сигналов от шумов и более высокую разрешающую способность, чем типовые виды частотной фильтрации 
[10]. Другим направлением исследований типпера являлось получение удельного электрического сопротивления (УЭС) среды. В результате был разработан трансформационный фильтр, который преобразует измеренные отношения $H_{z} / H_{\varphi}$ в кажущиеся сопротивления [11]. Чуть позднее был предложен улучшенный вариант этого способа, позволяющий получить тензор импеданса от магнитных полей с помощью преобразований Гильберта [12]. Однако более достоверным и надежным способом получения данных об электрических свойствах разреза являются прямые измерения импеданса, с дальнейшим пересчетом в УЭС, реализуемые в варианте $V L F-R$. В этом случае проводится регистрация электрической компоненты поля $E_{r}$ в направлении станции и поперечная ей магнитная составляющая $H_{\varphi}$. Отношение этих компонент сигнала определяет импеданс (волновое сопротивление) среды $Z=E_{r} / H_{\varphi}$, пропорциональный удельному электрическому сопротивлению подстилающих пород. В отечественной литературе модификацию радиокип $V L F-R$ иногда называют радиоэлектромагнитным профилированием (РЭМП). Импедансные измерения позволяют получать большие массивы кажущихся сопротивлений по площади работ, поэтому часто используются при геологическом картировании. При этом профильные наблюдения можно пересчитать в двухслойные геоэлектрические разрезы с помощью оптимизированных алгоритмов обработки магнитотеллурических данных. Данная технология интерпретации набирает все большую популярность у ряда исследователей $[13,14]$, а для повышения достоверности опробуется методика совместной обработке импедансных данных и типпера [15]. Целью представленной работы является оценка информативности геоэлектрических разрезов радиокип при изучении коры выветривания и кровли коренных пород в различных геологических условиях. К основным задачам исследований относится сравнение результатов радиокип с другими методами электромагнитных зондирований в рудных районах Среднего Урала.

\section{Методика работ}

Полевые измерения методом радиокип проводились двухканальным универсальным приемником «OМАР-2м» оригинальной разработки [16]. Использовались наблюдения ортогональных компонент электромагнитного поля сигналов сверхдлинноволновых радиостанций системы дальней навигации РСДН-20 «Альфа». Характер работы станций и особенности принимаемых сигналов рассматривались ранее в [17]. Электрическая составляющая $E_{r}$ снималась с симметричной стелющейся линии, протягиваемой вдоль профиля. Opтогональная магнитная компонента $H_{\varphi}$ измерялась с помощью малогабаритной ферритовой антенны, настроенной в резонанс на частоту станции 12,65 кГц. Сигналы электрического и магнитного каналов усиливались до необходимого уровня и записывались в цифровой регистратор. Одновремен- ная регистрация составляющих электромагнитного поля проводилась в течении 20-30 секунд на каждой точке. Результаты измерений, в виде модуля и фазы импеданса, пересчитывались в кажущиеся сопротивления $\rho_{\mathrm{k}}$ по формуле, принятой в магнитотеллурике [18]:

$$
\begin{gathered}
\rho_{\mathrm{r}}=(1 / \omega \mu) \cdot|Z|^{2}=(1 / \omega \mu) \cdot\left|E_{r} / H_{\varphi}\right|^{2}, \\
\varphi_{Z}=\varphi_{E}-\varphi_{H},
\end{gathered}
$$

где $\mu=\mu_{0}$ - магнитная проницаемость свободного пространства; $\omega$ - угловая частота измерения; $Z-$ поверхностный импеданс; $\varphi_{Z}-$ фаза импеданса; $\varphi_{E}$, $\varphi_{H}-$ фазы электрической и магнитной компонент сигналов.

Полученные значения кажущихся сопротивлений (КС) и фаз импеданса можно определенным способом преобразовать в параметры двухслойного разреза. В однородном изотропном пространстве КС является истинным удельным электрическим сопротивлением, а фазовый сдвиг между горизонтальными компонентами электрического и магнитного полей равен $45^{\circ}$. В слоистой среде фазовый сдвиг изменяется от нуля до $90^{\circ}$ в зависимости от величины и контрастности сопротивления слоев. Для проведения инверсии импедансных данных радиокип СДВР использовалась программа 2LAYINV, разработанная в финском университете Оулу [19]. Она основана на традиционных алгоритмах обработки магнитотеллурических данных, оптимизированных для двухслойной модели среды. $\mathrm{Pa-}$ нее проведенные исследования показали, что инверсия данных радиокип СДВР позволяет получать вполне адекватные геоэлектрические разрезы. В большинстве случаев они соответствуют двухслойной модели с хорошо проводящими поверхностными отложениями и высокоомными коренными породами. Недостаток технологии заключается в замещении нескольких осадочных слоев эквивалентным слоем, что делает невозможным расчленение рыхлых отложений и вносит искажения в получаемые значения УЭС [20]. К достоинствам программы 2LAYINV относится вычисление минимальных и максимальных значений параметров разреза, укладывающихся в модель инверсии с учетом погрешности полевых данных. Это позволяет получить «вероятностный» характер изменений удельных электрических сопротивлений и глубины залегания границы. Чтобы оценить достоверность получаемых разрезов радиокип, на эталонных геологических объектах проводились исследования другими электроразведочными методами. К ним, в первую очередь, относятся аудиомагнитотеллурические (АМТ) и вертикальные электрические зондирования (ВЭЗ). Полевые работы ВЭЗ осуществлялись по стандартной методике наблюдений [21], для интерпретации использовалась известная программа IPI2Win, разработанная на кафедре геофизики МГУ им. М.В. Ломоносова. АМТ измерения выполнялись в варианте экспресс-зондирований, результаты трансформировались в глубинные разрезы с учетом априорной информации о верхней части разреза [22]. 


\section{Результаты исследований}

Крылатовский рудник

Исследуемый участок находится в 35 км на юго-запад от г. Екатеринбурга, в районе Крылатовско-Чесноковского месторождения золота, известного с 1803 г. Район работ располагается в пределах южного окончания Новоалексеевского плагиогранитного массива, ограниченного с запада региональным Серовско-Маукским (Дегтярским) разломом, с востока - Крылатовским разрывом. Массив формировался в тектонически активной зоне, что подтверждается развитием в нем многочисленных разрывных нарушений и мощных зон рассланцевания. Впоследствии он подвергся многостадийному гидротермальному воздействию. Крылатовское месторождение представляет собой серию минерализованных кварцевых жил, залегающих в кварц-серицитовых метасоматитах (сланцеватых березитах) [23]. Известны несколько крупных золотонос- ных жил, вытянутых в меридиональном направлении, длиной 550-2350 м и мощностью 2,5..6,7 м, являвшихся предметом шахтной добычи Крылатовского рудника. Содержание золота неравномерное, связано в основном с небольшим количеством сульфидов, поэтому руды использовались в качестве золотоносных кварцевых флюсов. На момент закрытия на руднике функционировали три шахты: Центральная (490 м), Южная Вентиляционная $(190 \mathrm{~m})$ и Северная Вентиляционная (370 м) [24]. Крылатовский рудник прекратил свою работу в 2006 г., а через два года произошло полное затопление горных выработок с выходом шахтных вод на поверхность земли. Территория пос. Крылатовский была подтоплена, а процессы сдвижения в районе шахты Северная Вентиляционная вызвали образование провала глубиной 40 м. Величина воронки составила $80 \times 300$ м, в результате образовался водоем длиной около $200 \mathrm{м}$ и шириной от 30 до $50 \mathrm{m.}$

a)

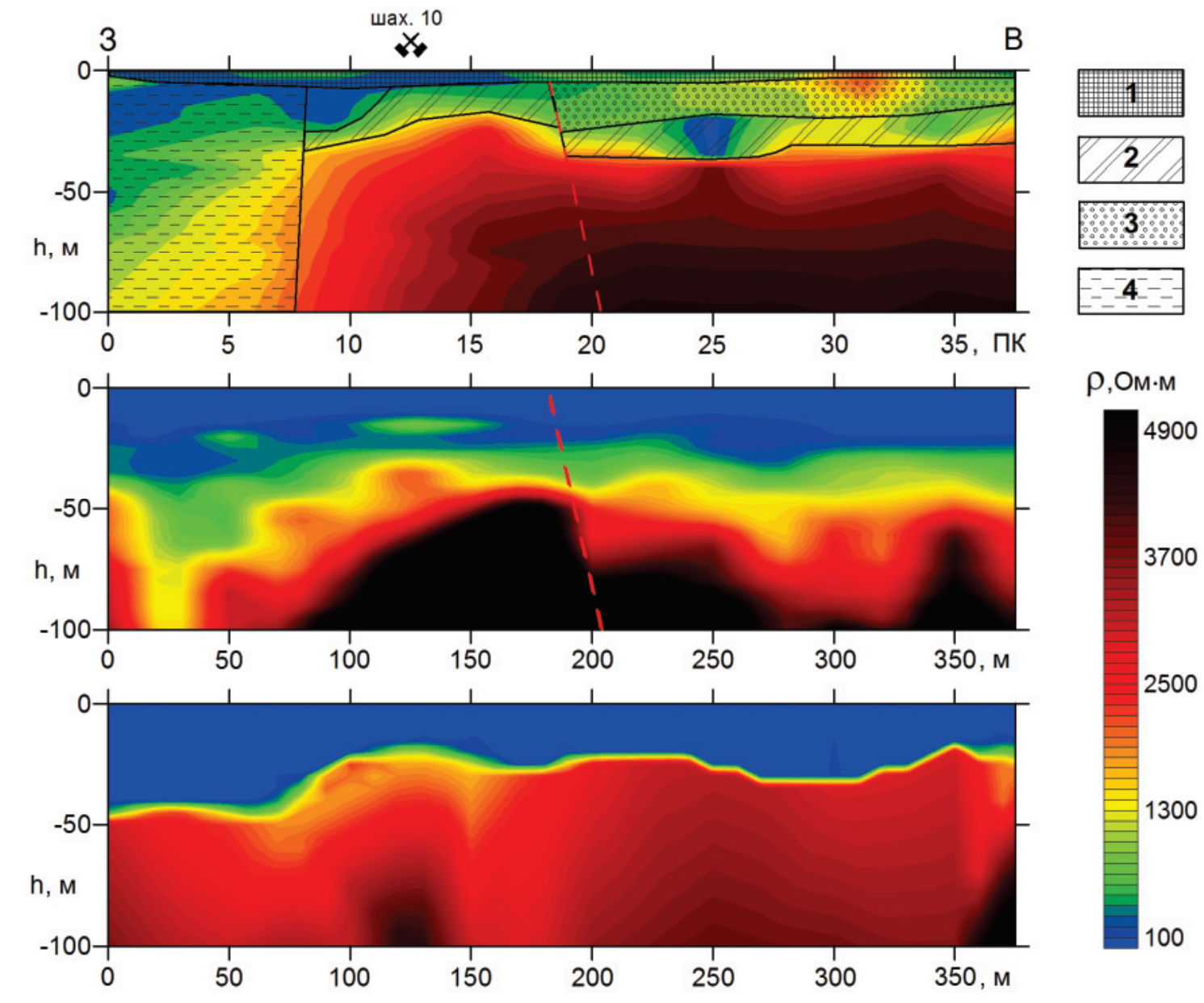

Pис.1. Результаты электролагнитных зондирований на Крылатовском руднике: а) геоэлектрический разрез ВЭЗ; б) трансформированный разрез АМТЗ; в) результат инверсии радиокип СДВР. Условные обозначения: 1) насыпные грунты; 2 ) низкоомная ко ра выветривания; 3) высокоомная кора выветривания; 4) обводненная зона. Красныл пунктирол показано тектоническое на рушение, значком обозначено положение шахты 10

Fig. 1. Results of electromagnetic soundings at the Krylatovsky mine: a) geoelectric section of Vertical Electrical Sounding (VES); $b$ ) transfor med section of audiomagnetotelluric (AMT) sounding; $c$ ) VLF-R inversion results. Legend: 1) bulk soils; 2) low resistance weathering crust; 3) high resistance weathering crust; 4) flooded area. The red dotted line shows tectonic fracture, the icon indicates the position of the mine 10 
Геолого-геофизические исследования, включающие несколько методов электромагнитных $30 \mathrm{H}^{-}$ дирований, проводились в центральной части шахтного поля, приблизительно в 200 м южнее провала, поблизости от ликвидированной шахты 10 . Цель работ заключалась в оценке опасности образования новых просадок поверхности. К задачам электроразведочных методов относилось определение общей мощности рыхлых отложений и степени обводненности горных пород.

По результатам вертикальных электрических зондирований верхняя часть разреза (ВЧР) состоит из 4-5 геоэлектрических слоев. Мощность слоев невыдержанная, также наблюдаются резкие изменения удельных электрических сопротивлений (УЭС) в пределах одного слоя. Сложное строение разреза подтверждается и аудиомагнитотеллурическими зондированиями (АМТЗ) (рис. 1).

По данным ВЭЗ коренные породы в основании разреза характеризуются сопротивлениями 1500-2000 Ом·м и выше. Перекрывающая их кора выветривания (2), мощностью 15-20 м, имеет УЭС в пределах 50-200 0м·м. Следующий выделяемый слой (3) наблюдается только к востоку от ПК20, он имеет мощность 10-15 м и отличается повышенным сопротивлением ( $\rho=500-800$ Ом·м). В западной части профиля присутствует мощная зона (4) пониженных сопротивлений ( $\rho=100$ Ом·м), связанная с дезинтеграцией и обводнением пород в районе подземных выработок. Верхи разреза до 5 м (1) характеризуется сильным разбросом УЭС от 18 до 1500 Ом·м, в отдельных местах с переслаиванием разнородного материала, что соответствует техногенным насыпным грунтам. Результаты AMT3 неплохо согласуются с вертикальными электрическими зондированиями. Особенно хорошо выделяется зона шахтной подработки горизонта 71 м на ПК2-ПК7 и тектоническое нарушение в районе ПК20 (рис. 1 , б). Некоторое несоответствие УЭС, полученных двумя методами, связано с разными особенностями протекания гальванических (ВЭЗ) и вихревых (АМТЗ) токов. Двухслойный разрез, построенный по данным радиокип СДВР, не может отобразить всех особенностей геоэлектрического строения, но позволяет определить основную границу между коренными породами и рыхлыми отложениями. Так, уверенно выделяется поднятие вблизи шахты 10 , характерное для всех геоэлектрических разрезов. Участок подземных горных работ в начале профиля отметился на разрезе радиокип в виде резкого увеличения мощности рыхлых образований (рис. 1,8$)$. Результаты всех электроразведочных методов указывают на потенциальную опасность дальнейшей просадки поверхности земли в районе затопленных подземных выработок (ПК0-ПК7).

\section{Кунгурский профиль}

Участок опытно-методических работ находится в Дегтярском рудном районе, в километре к югу от Кунгурского никель-кобальтового месторожде- ния. Контрольный профиль длиной 600 м расположен в пределах Тагильского прогиба со сложным комплексом пород приконтактовой зоны Серовско-Маукского разлома. $\mathrm{K}$ разлому приурочен пункт медной минерализации вблизи профиля (№ 1439) и Кунгурковское медно-цинковое проявление в 1,5 км к юго-западу. В начале профиля (ПК0-ПК20) в основании разреза залегают мраморированные известняки, за которыми следуют серпентиниты (ПК20-ПК35). В конце профиля (ПК35-ПК60) распространены вулканогенные породы, состоящие из порфиритов, кварцевых альбитофиров и их туфов. Геофизическими исследованиями выяснено, что горные породы обладают разными электрофизическими свойствами с характерной широтной зональностью изменения электрического сопротивления и крутым восточным падением границ (рис. 2).

По результатам электромагнитных зондирований удельные электрические сопротивления известняков имеют довольно высокие значения $(\rho>2000$ Ом·м). Они обладают развитой низкоомной корой выветривания ( $\rho=30-50$ Ом·м), что может свидетельствовать о значительном содержании в ее составе глинистой компоненты. Серпентиниты и порфириты характеризуются близкими значениями УЭС: 800-1300 Ом·м по данным ВЭЗ и 1300-2500 Ом·м - по радиокип. Кора выветривания серпентинитов отличается крайней невыдержанностью, как по мощности (от 10 до 25 м), так и по УЭС (от десятков до сотен Ом·м). В ней отмечается присутствие локальных высокоомных объектов ( $\rho>1000$ Ом·м), которые могут представлять собой останцы скальных пород. Над вулканогенными породами мощность осадков увеличивается до $35 \mathrm{~m}$, удельные сопротивления составляют 400-600 Ом·м по ВЭЗ и 200-300 Ом·м - по данным радиокип. Поверхностный слой от 2 до 5 м имеет дресвяно-щебенистый состав ( $\rho=140-290$ Ом·м), а в начале профиля (ПК0-ПК16) - с прослойкой глины ( $\rho=10-16$ Ом·м). Вертикальные электрические зондирования позволяют довольно детально расчленить геологический разрез по электрическим свойствам. Радиокип в основном позволяет выделить характерные особенности коренных пород, таких как рельеф поверхности и величины сопротивлений. Что касается рыхлых отложений, то здесь возможности радиокип ограничены из-за использования упрощенной (двухслойной) физикогеологической модели. В целом геоэлектрические разрезы хорошо согласуются между собой и соответствуют реальной геологической обстановке.

\section{Волчихинский профиль}

Участок работ расположен в зоне полимиктового меланжа Серовско-Маукского разлома, разделяющего вулканогенные породы Тагильской и Восточно-Уральской мегазон. Профиль начинается в долине р. Ельчевка, текущей по ослабленной зоне разлома, и идет на восток вкрест простирания уральских структур, в сторону Волчихинского водохранили- 


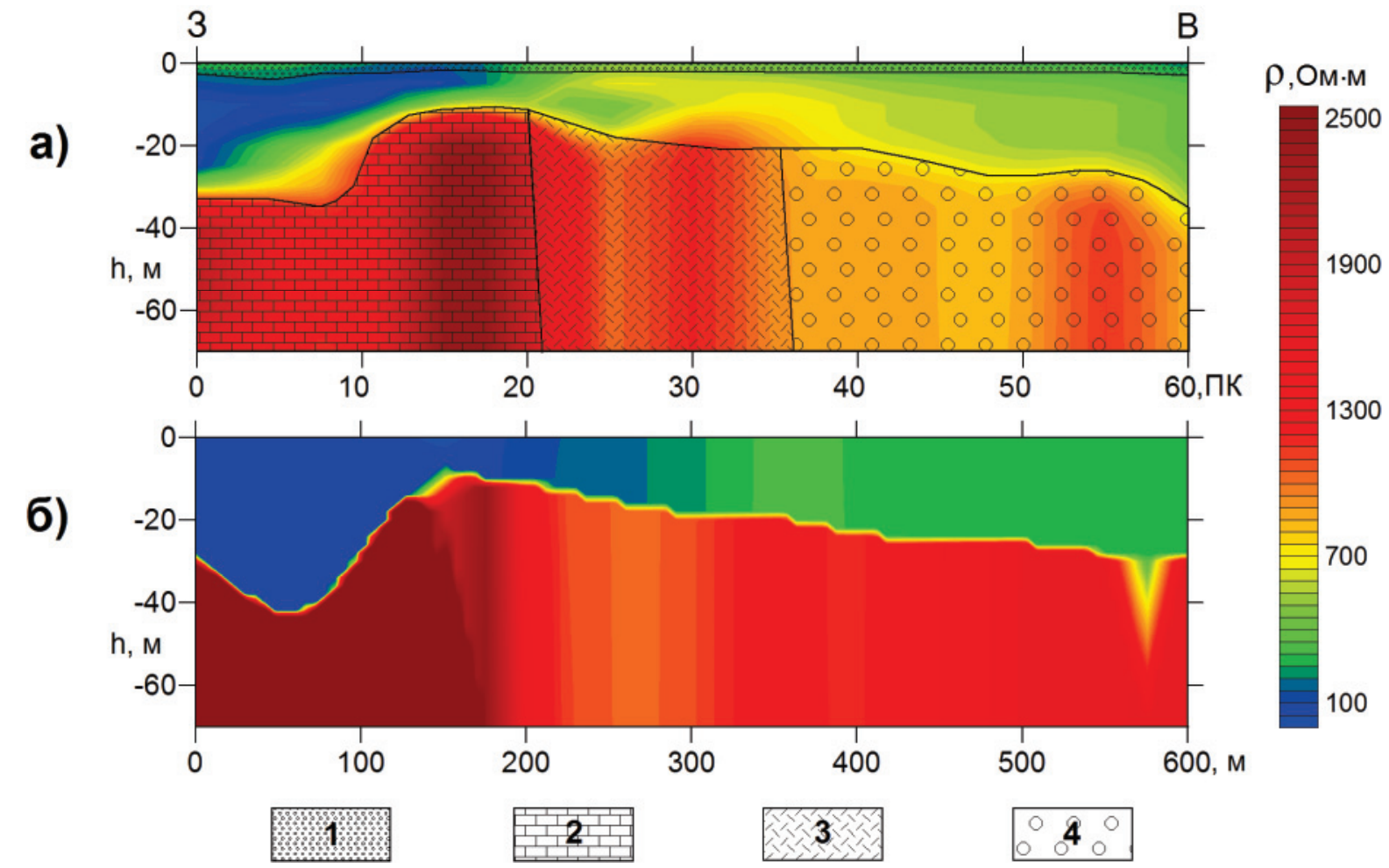

Pис. 2. Результаты электролагнитных зондирований на Кунгурском профиле: а) геоэлектрический разрез ВЭЗ; б) результат инвер сии радиокип СДВР. Условные обозначения: 1) дресвяно-щебенистый грунт; 2) известняки; 3) серпентиниты; 4) порфириты u myфы

Fig. 2. Results of electromagnetic soundings on the Kungur profile: a) geoelectric section of VES; b) VLF-R inversion results. Legend: 1) finegravelly soil; 2) limestone; 3) serpentinites; 4) porphyrites and tuffs

ща. Основная часть профиля (ПК15-ПК50) сложена базальтами и туфопесчаниками дегтярской свиты, вмещающими колчеданное медно-цинковое и полиметаллическое оруденение. На прилегающей территории обнаружен целый ряд старых горных выработок, пройденных в меридиональном направлении. К зоне меланжа также тяготеет силикатно-никелевое оруденение, связанное с серпентинитами Серовско-Маукского пояса, контактирующими с мраморизованными известняками. Данный тип оруденения локализуется в карстовых полостях верхней части карбонатной толщи. В нескольких километрах к северу расположено Петровское никель-кобальтовое малое месторождение, на юге известно три рудопроявления контактово-карстового типа [25].

На Волчихинском профиле были проведены электроразведочные работы методами АMT3, радиокип СДРВ и ДИЗ (дистанционные индукционные зондирования). Малоглубинные индукционные зондирования показали, что кора выветривания дегтярской свиты составляет около 10 м, что подтверждается результатами других методов (рис. 3).

Начало профиля характеризуется низкими значениями сопротивлений за счет увеличенной мощности рыхлых отложений до 50 м и повышенной трещиноватости коренных пород в зоне мелан- жа. Резкий перепад рельефа основания разреза в районе ПК10-ПК15 соответствует восточной границе Серовско-Маукского разлома. Смена геологической обстановки отображается всеми электрометрическими методами. На разрезах АМТЗ и радиокип СДРВ также хорошо выделяются оперяющие тектонические нарушения (ПК36 и ПК42) по характерному аномальному снижению УЭС. Сравнивая полученные разрезы можно констатировать, что результат инверсии радиокип имеет все структурные особенности, присущие АМТЗ, но обладает большей контрастностью в отношении границы коренных пород. Учитывая приуроченность сульфидной минерализации к зонам тектонических нарушений (по старым выработкам), можно спрогнозировать рудную перспективность участка в интервале ПК33-ПК45.

\section{Чусовское месторождение}

Чусовское медно-колчеданное месторождение расположено в Полевском районе Свердловской области. Прилегающая территория охватывает зону сочленения южной части Тагильского прогиба с западной границей Восточно-Уральского поднятия. Граница между указанными структурами первого порядка проходит по Дегтярскому сдвигу. Чусовское месторождение располагается в пределах Полевской мегасинклинали и приурочено к 


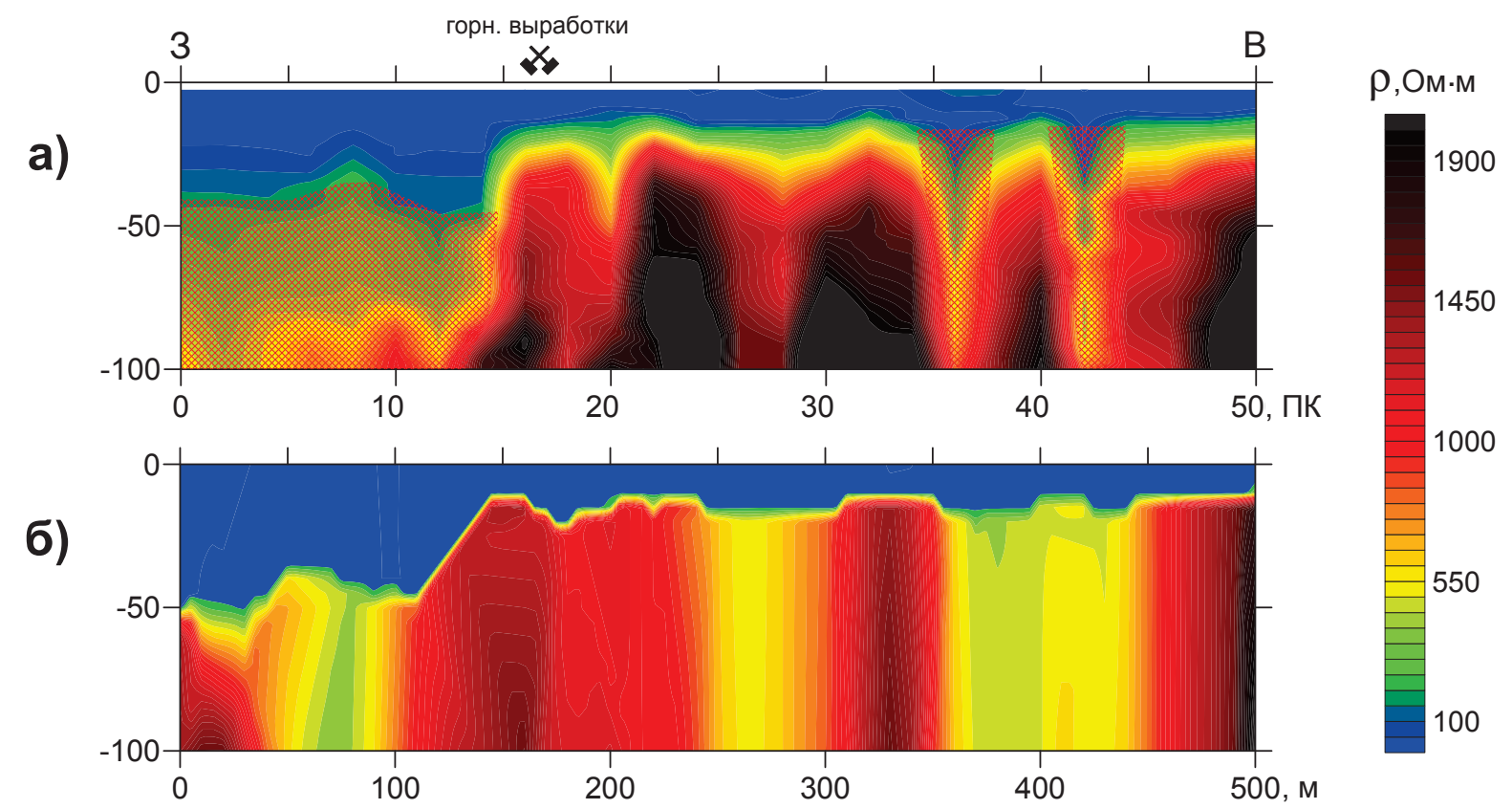

Pис. 3. Результаты электролагнитных зондирований на Волчихинском профиле: а) трансфорлированный разрез АМтЗ; б) результат инверсии радиокип СДВР. Штриховкой выделены зоны тектонических нарушений

Fig. 3. Results of electromagnetic soundings on the Volchikhinsky profile: a) transformed section of AMT; b) VLF-R inversion results. Hatching highlighted zones of tectonic fractures

меридионально вытянутой Чусовско-Поварнинской зоне метаморфических сланцев, залегающих среди зеленокаменных пород (альбитофиры, порфироиды, серпентиниты). Месторождение открыто в ходе разведочного бурения и представлено системой жилообразных тел, сложенных густыми вкрапленниками с линзами и прожилками сплошных колчеданов, залегающих согласно сланцеватости метаморфических сланцев. Рудоносная зона не имеет выхода на поверхность («слепое» тело) и располагается на глубине от 30 до 300 м. Основное рудное тело мощностью до 10 м имеет меридиональное простирание и восточное падение под углом $60-70^{\circ}$.

Из-за небольшого размера и значительной глубины залегания Чусовское месторождение не разрабатывалось, однако на нем проведен большой объем разведочного бурения и каротажа скважин. По электрокаротажным данным удельные электрические сопротивления горных пород меняются в широких пределах. Зеленокаменные породы обладают самым высоким сопротивлением (2000-10000 Ом·м). Метаморфические сланцы характеризуются значениями от 300 до $1500 \mathrm{OM} \cdot \mathrm{M}$, снижающимися до 50-300 Ом·м, при обогащении сульфидами. Низкими УЭС выделяются поверхностные отложения (10-20 Ом·м), рудные зоны (10-100 Ом·м) и сплошные колчеданы (менее 1 Ом·м) [26]. В течение длительного времени месторождение служит в качестве контрольного полигона для опытно-методических и научных работ. На нем испытано множество геофизических методов исследований, в том числе несколь- ко видов электромагнитных зондирований. Наиболее детально представлен разрез аудиомагнитотеллурических зондирований, с которым сопоставлен результат интерпретации радиокип СДРВ (рис. 4).

Проведенные исследования свидетельствуют, что толщина рыхлых отложений в западной части профиля не превышает 10 м и снижается в восточном направлении до полуметра. Однако над рудным телом наблюдается резкое увеличение мощности осадков до 15-20 м. По результатам обоих методов, УЭС коренных пород отличаются стабильно высокими значениями (2000-5000 Ом·м и выше), только в околорудной зоне сопротивления снижаются до 700-1500 0м·м. Ранее на прилегающей территории были выполнены поисково-разведочные работы на колчеданное оруденение с привлечением геофизики, которые не привели к положительному результату. Причиной может являться недостаточная детальность съемки. Геофизические работы ставились исходя из результатов каротажа, в предположении о высокой контрастности руд и широкой зоне сульфидной минерализации. Наземные исследования опровергают это предположение. Ширина околорудных изменений, уверенно выделяемых электромагнитными зондированиями, составляет всего 20 м. Следовательно, шаг съемки для обнаружения рудного объекта должен составлять не более 6 м. Традиционные электроразведочные методы малопроизводительны при данном шаге наблюдений, следовательно, слишком затратные. Метод радиокип более эффективен, поскольку позволяет проводить 
a)

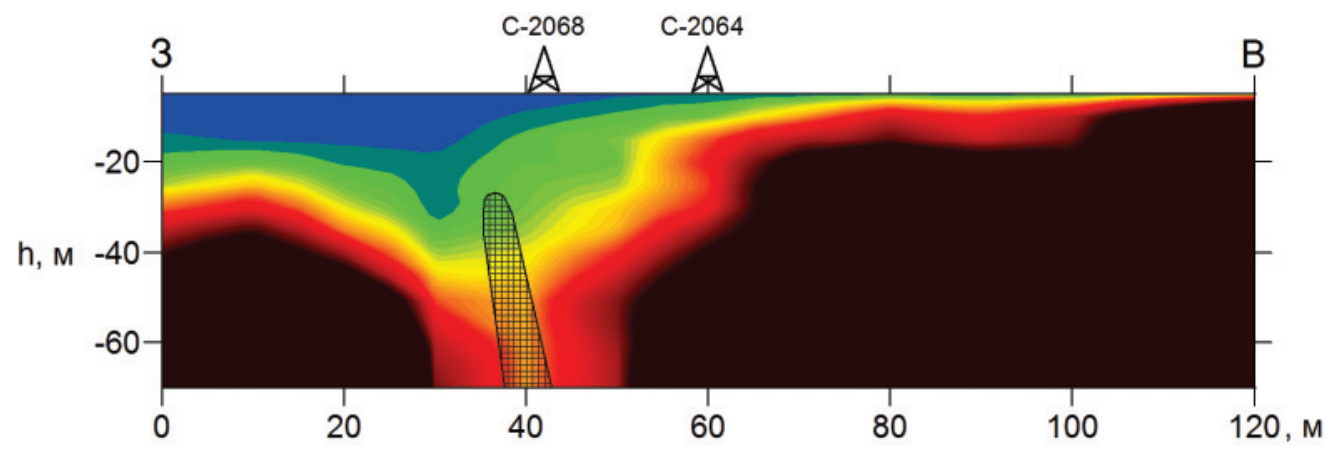

б)

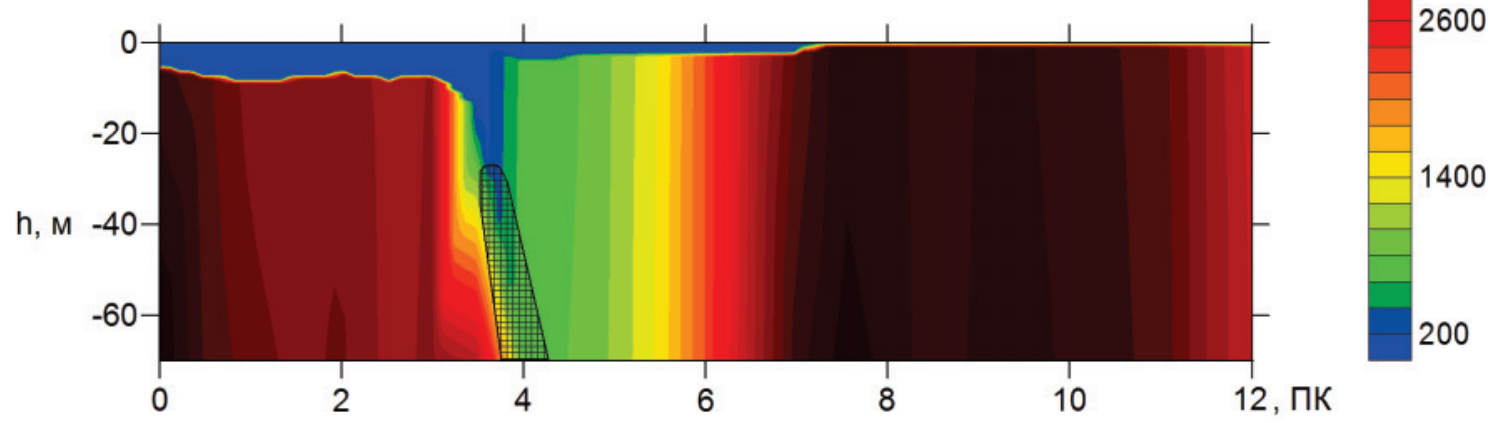

Pис.4. Результаты электромагнитных зондирований на Чусовском медно-колчеданном месторождении: а) трансформированный разрез АМТЗ; б) результат инверсии радиокип СДВР

Fig. 4. Results of electromagnetic soundings at the Chusouskoye copper-pyrite deposit: a) transformed section of AMT; $b$ ) VLF-R inversion results

быструю съемку за счет безгенераторной технологии. Сравнительные результаты указывают на принципиальную возможность обнаружения «слепых» рудных тел, залегающих на большой глубине, с помощью относительно малоглубинного, но производительного метода радиокип СДРВ. Ряд исследователей считает, что перспективность Дегтярско-Полевского рудного района остается высокой [27], и детальная доразведка может привести к обнаружению новых месторождений.

\section{Заключение}

Проведенные исследования показали хорошую сопоставимость результатов инверсии радиокип СДВР с геоэлектрическими разрезами, полученными другими методами электромагнитных зон-

\section{СПИСОК ЛИТЕРАТУРЫ}

1. Тархов А.Г. Основы геофизической разведки методом радиокип. - М.: Госгеолтехиздат, 1961. - 213 с.

2. Гордеев С.Г., Седельников Э.С., Тархов А.Г. Электроразведка методом радиокип. - М.: Недра, 1981. - 132 с.

3. Ogilvy R.D. An appraisal of the VLF ground resistivity technique as an aid to mineral exploration // Mineral Reconnaissance Programme Rep. Inst. Geol. Sci. - 1980. - № 36. - P. 1-20.

4. McNeill J.D., Labson V.F. Geological mapping using VLF radio fields // Electromagnetic Methods in Applied Geophysics. 1991. - V. 2. - P. 521-640.

5. Paterson N.R., Ronka V. Five years of surveying with very low frequency - electromagnetics method // Geoexpl. - 1971. № 9. - P. 7-26. дирований. Радиокип не может отобразить всех особенностей строения верхней части разреза, но позволяет выделить характерные черты коренных пород и определить основную границу между рыхлыми отложениями и основанием разреза. Полученные результаты указывают на принципиальную возможность обнаружения глубокозалегающих рудных объектов с помощью метода радиокип СДРВ. Метод отличается хорошей производительностью, поэтому можно добиться высокой детальности наблюдений при небольших затратах. Геоэлектрические разрезы радиокип могут использоваться для оперативной оценки общей мощности коры выветривания и выбора точек зондирований другими электромагнитными методами для уточнения геологической обстановки.

6. Fraser D.C. Contouring of VLF-EM data // Geophysics. - 1969. № 34. - P. 958-967.

7. Karous M., Hjelt S.E. Linear filtering of VLF dip-angle measurements // Geophysical Prospecting. - 1983. - № 31. - P. 782-794.

8. Jeng Y., Lin M.-J., Chen C.-S., Wang Y.-H. Noise reduction and data recovery for a VLF-EM survey using a nonlinear decomposition method // Geophysics. - 2007. - № 72. - P. F223-F235.

9. Lin M.-J., Jeng Y. Application of the VLF-EM method with EEMD to the study of a mud volcano in southern Taiwan // Geomorphology. - 2010. - № 119. - P. 97-110.

10. Давыдов В.А., Давыдов А.В. Очистка геофизических данных от шумов с использованием преобразования Гильберта-Хуанга // Актуальные инновационные исследования: наука и практика. - 2010, - № 1. - С. 1-26. 
11. Chouteau M., Zhang P., Chapellier D. Computation of apparent resistivity profiles from VLF-EM data using linear filtering // Geophys. Prosp. - 1996. - № 44. - P. 215-232.

12. Gharibi M., Pedersen L.B. Transformation of VLF data into apparent resistivities and phases // Geophysics. - 1999. - № 64. P. 1393-1402.

13. VLF-MT Survey around Nakadake crater at Aso Volcano / A. Harja, W. Srigutomo, Y. Tanaka, T. Kagiyama, D. Sutarno // IOP Conference Series: Earth and Environmental Science. - 2016. V. 29. - № 1. - P. 1-8.

14. Subsurface Structure Mapping Using Geophysical Data in Candi Umbul-Telomoyo, Magelang, Central Java, Indonesia / A.P. Affanti, E. Prastyani, P.D. Maghfira, S.W. Niasari // Journal of Physics: Conference Series. - 2018. - V. 1011. - № 1. P. 012027 (1-5).

15. Prastyani E., Niasari S.W. Interpretation of VLF-EM \& VLF-R data using tipper and impedance analyses: A case study from Candi Umbul-Telomoyo, Magelang, Indonesia // $1^{\text {st }}$ International Geo-Electromagnetic Workshop (GEO-EM 2017). AIP Conference Proceedings. - West Java, Indonesia. - 2017. - V. 1861. - № 1. P. 030017 (1-4).

16. Давыдов В.А. Универсальный полевой геофизический приемник ОМАР-2 // Приборы и техника эксперимента. - 2016. № 6. - C. 127-128.

17. Давыдов В.А. Электроразведка методом радиокип в сверхдлинноволновой модификации с использованием радиостанций системы дальней навигации РСДН-20 («Альфа») // Инженерные изыскания. - 2014. - № 2. - С. 65-70.

18. Cagniard L. Basic theory of the magnetotelluric method in geophysical prospecting // Geophysics. - 1953. - № 18. P. 605-635.

19. Pirttijärvi M. 2LAYINV - Laterally constrained two-layer inversion of VLF-R measurements. User's guide. - Oulu: University of Oulu, 2006. $-12 \mathrm{p}$.

\section{Информация об авторах}

Давыдов В.А., кандидат геолого-минералогических наук, старший научный сотрудник лаборатории экологической геофизики Института геофизики им. Ю.П. Булашевича Уральского отделения РАН.
20. Давыдов В.А. Интерпретация импедансных данных радиокип сверхдлинноволновых радиостанций с построением двухслойных геоэлектрических разрезов // Известия вузов. Горный журнал. - 2018. - № 1. - С. 99-106.

21. Инструкция по электроразведке / под ред. Г.С. Франтова. - Л.: Недра, 1984. - 352 с.

22. Давыдов В.А. Способ преобразования аудиомагнитотеллурических данных с учетом априорной информации // Геофизические исследования. - 2016. - Т. 17. - № 4. - С. 57-66.

23. Золотооруденение Екатеринбургского геологического полигона / В.Н. Сазонов, В.Н. Огородников, Ю.А. Поленов и др. - Екатеринбург: УГГГА, 1997. - 226 с.

24. Зонирование природно-техногенных гидрогеологических систем (на примере Крылатовского рудника) / С.Н. Елохина, В.А. Арзамасцев, С.Э. Борич, Е.М. Сотова, В.А. Щапов // Известия вузов. Геология и разведка. - 2010. - № 1. - С. 57-66.

25. Государственная геологическая карта Российской Федерации. Масштаб 1:200000. Издание второе. Серия Среднеуральская. Лист 0-41-XXV. Объяснительная записка / Р.Д. Калугина, В.Ф. Копанев, Е.В. Стороженко и др. - М.: Московский филиал ФГБУ «ВСЕГЕИ», 2017. - 156 с.

26. Сравнительная характеристика методов скважинной электроразведки (по материалам Чусовского колчеданного месторождения) / П.Ф. Родионов, С.А. Жданов, А.А. Кожевников, И.И. Кононенко // Теория и практика электрометрии. Свердловск: РИСО УНЦ АН СССР, 1972. - С. 164-176.

27. Жданов С.А., Пыжьянов Ю.Б. Результаты работ по обобщению геолого-геофизических материалов в Дегтярско-Полевском районе // Леса России и хозяйство в них. - 2011. № 1 (38). - C. 19-26.

Поступила 23.11.2018 2. 
UDC 550.837.74

\title{
OPPORTUNITIES OF VLF METHOD WHEN STUDYING THE TOP SECTION IN ORE AREAS
}

\author{
Vadim A. Davydov, \\ davyde@yandex.ru \\ Bulashevich Geophysics Institute, Ural Branch of RAS. \\ 100, Amundsen street, Yekaterinburg, 620016, Russia.
}

The relevance of the research is caused by the economic interest in using simple, efficient and high-performance geophysical technologies for prospecting and exploration of ore deposits.

The main aim of the research is to evaluate the information content of geoelectrical sections, built on the impedance data of the Very Low Frequency (VLF) method, when studying the weathering crust and the bedrock in various geological conditions.

Objects of the research are located in the Degtyarsko-Polevsky ore region of the Middle Urals, in the contact zone of the SerovskoMauksky Fault, separating the rock complexes of the Tagil trough and the East Ural uplift. Geophysical profiles were located on the territory of the Krylatovsky gold-quartz deposit, the Chusovskoe copper-pyrite deposit, the Kungursky and Volchikhinsky areas.

Methods. Field measurements were carried out with a OMAR-2m wideband receiver with a creeping line and an inductive sensor of an alternating magnetic field. Observations of the orthogonal components of the very low frequency radio station signal field were made. As a comparison, we used the results of audio magnetotelluric and vertical electrical soundings, as well as information on the geological stu$d y$ of the territory. Quantitative processing of electrical data was carried out using software developed in various scientific institutions. Results. Studies have shown good comparability of the results of very low frequency inversion with the geoelectric sections obtained by other methods of electromagnetic sounding. A very low frequency method cannot display all the structural features of the upper part of the section, but makes it possible to single out the characteristic features of bedrock and to determine the main boundary between the loose sediments and the base of the section. The obtained results indicate that it is possible in principle to detect deep-laying ore objects using the very low frequency method. The method has a good performance, so you can achieve high detail observations at low cost. The geo-electric sections of the very low frequency can be used to quickly assess the total thickness of the weathering crust and select sounding points by other electromagnetic methods to clarify the geological situation.

Key words:

Very Low Frequency method, components of electromagnetic field, impedance, geoelectrical section, ore deposit.

\section{REFERENCES}

1. Tarhov A.G. Osnovy geofizicheskoy razuedki metodom radiokip [Fundamentals of geophysical intelligence by VLF method]. Moscow, Gosgeoltekhizdat Publ., 1961. 213 p.

2. Gordeev S.G., Sedelnikov E.S., Tarkhov A.G. Elektrorazvedka metodom radiokip [Electrical survey by VLF method]. Moscow, Nedra Publ., 1981. 132 p.

3. Ogilvy R.D. An appraisal of the VLF ground resistivity technique as an aid to mineral exploration. Mineral Reconnaissance Programme Rep. Inst. Geol. Sci., 1980, no. 36, pp. 1-20.

4. McNeill J.D., Labson V.F. Geological mapping using VLF radio fields. Electromagnetic Methods in Applied Geophysics, 1991, vol. 2, pp. 521-640.

5. Paterson N.R., Ronka V. Five years of surveying with very low frequency - electromagnetics method. Geoexpl., 1971, no. 9, pp. $7-26$.

6. Fraser D.C. Contouring of VLF-EM data. Geophysics, 1969, no. 34 , pp. 958-967.

7. Karous M., Hjelt S.E. Linear filtering of VLF dip-angle measurements. Geophysical Prospecting, 1983, no. 31, pp. 782-794.

8. Jeng Y., Lin M.-J., Chen C.-S., Wang Y.-H. Noise reduction and data recovery for a VLF-EM survey using a nonlinear decomposition method. Geophysics, 2007, no. 72, pp. F223-F235.

9. Lin M.-J., Jeng Y. Application of the VLF-EM method with EEMD to the study of a mud volcano in southern Taiwan. Geomorphology, 2010, no. 119, pp. 97-110.

10. Davydov V.A., Davydov A.V. Ochistka geofizicheskikh dannykh ot shumov s ispolzovaniem preobrazovaniya Gilberta-Huanga [Clearing geophysical data from noise using the Hilbert-Huang transform]. Aktualnye innovatsionnye issledovaniya: nauka $i$ praktika, 2010, no. 1, pp. 1-26.

11. Chouteau M., Zhang P., Chapellier D. Computation of apparent resistivity profiles from VLF-EM data using linear filtering. Geophys. Prosp., 1996, no. 44, pp. 215-232.
12. Gharibi M., Pedersen L.B. Transformation of VLF data into apparent resistivities and phases. Geophysics, 1999, no. 64, pp. 1393-1402.

13. Harja A., Srigutomo W., Tanaka Y., Kagiyama T., Sutarno D. VLF-MT Survey around Nakadake crater at Aso Volcano. IOP Conference Series: Earth and Environmental Science, 2016, vol. 29, no. 1, pp. 1-8.

14. Affanti A.P., Prastyani E., Maghfira P.D., Niasari S.W. Subsurface Structure Mapping Using Geophysical Data in Candi UmbulTelomoyo, Magelang, Central Java, Indonesia. Journal of Physics: Conference Series, 2018, vol. 1011, no. 1, pp. 012027 (1-5).

15. Prastyani E., Niasari S.W. Interpretation of VLF-EM \& VLF-R data using tipper and impedance analyses: A case study from Candi Umbul-Telomoyo, Magelang, Indonesia. $1^{\text {st }}$ International GeoElectromagnetic Workshop (GEO-EM 2017). AIP Conference Proceedings, 2017, vol. 1861, no. 1, pp. 030017 (1-4).

16. Davydov V.A. Universalny polevoy geofizicheskiy priemnik OMAR-2 [Universal field geophysical receiver OMAR-2]. Pribory i tekhnika eksperimenta, 2016, no. 6, pp. 127-128.

17. Davydov V.A. Elektrorazvedka metodom radiokip v sverkhdlinnovolnovoy modifikatsii s ispolzovaniem radiostantsiy sistemy dalney navigatsii RSDN-20 ("Alfa») [Electrical survey by VLF method using radio stations of the RSDN-20 long-distance navigation system («Alpha»)]. Inzhenernye izyskaniya, 2014, no. 2, pp. $65-70$.

18. Cagniard L. Basic theory of the magnetotelluric method in geophysical prospecting. Geophysics, 1953, no. 18, pp. 605-635.

19. Pirttijärvi M. 2LAYINV - Laterally constrained two-layer inversion of VLF-R measurements. User's guide. Oulu, University of Oulu, Division of Geophysics, 2006.12 p.

20. Davydov V.A. Interpretation of the impedance data of the VLF radio stations with the construction of two-layer geoelectric sections. Izvestiya vuzov. Gornyy zhurnal, 2018, no. 1, pp. 99-106. In Rus. 
21. Instruktsiya po elektrorazvedke [Electrical Survey Instructions] Ed. by G.S. Frantov. Leningrad, Nedra Publ., 1984. 352 p.

22. Davydov V.A. Method for converting audio magnetotelluric data with regard to a priori information. Geofizicheskie issledovaniya, 2016, vol. 17, no. 4, pp. 57-66. In Rus.

23. Sazonov V.N., Ogorodnikov V.N., Polenov Yu.A. Zolotoorudenenie Ekaterinburgskogo geologicheskogo poligona [Gold mining of the Yekaterinburg geological test site]. Ekaterinburg, UGGGA Publ., 1997. $226 \mathrm{p}$.

24. Elokhina S.N., Arzamastsev V.A., Borich S.E., Sotova E.M., Shchapov V.A. Zonirovanie prirodno-tekhnogennykh gidrogeologicheskikh sistem (na primere Krylatovskogo rudnika) [Zoning of natural and man-made hydrogeological systems (for example, Krylatovsky mine)]. Izvestiya vuzov. Geologiya i razvedka, 2010, no. 1. pp. 57-66.

25. Kalugina R.D., Kopanev V.F., Storozhenko E.V. Gosudarstvennaya geologicheskaya karta Rossiyskoy Federatsii. Masshtab
1:200000. Seriya Sredneuralskaya [State geological map of the Russian Federation. Scale 1:200000. Series Sredne-Ural]. Moscow, Moskovskiy filial FGBU «VSEGEI» Publ., 2017. 156 p.

26. Rodionov P.F., Zhdanov S. A., Kozhevnikov A.A., Kononenko I.I. Sravnitelnaya kharakteristika metodov skvazhinnoy elektrorazvedki (po materialam Chusovskogo kolchedannogo mestorozhdeniya) [Comparative characteristics of downhole electrical survey methods (based on materials from the Chusovskoy pyrite field)]. Teoriya i praktika elektrometrii [Theory and practice of electrometry]. Sverdlovsk, RISO UNC AN SSSR, 1972. pp. 164-176.

27. Zhdanov S.A., Pyzhyanov Yu.B. The results of the generalization of geological and geophysical materials in the Degtyarsko-Polevsky district. Lesa Rossii i khozyaystvo v nikh, 2011, no. 1 (38), pp. 19-26.

Received: 23 November 2018.

\section{Information about the authors}

Vadim A. Davydov, Cand. Sc., senior researcher, Bulashevich Geophysics Institute, Ural Branch of RAS. 